\title{
FGFR/VEGFR/PDGFR/FLT3/SRC Inhibitor XL999
}

National Cancer Institute

\section{Source}

National Cancer Institute. FGFR/VEGFR/PDGFR/FLT3/SRC Inhibitor XL999. NCI Thesaurus. Code C116894.

A small molecule inhibitor of numerous tyrosine kinases (TKs) including fibroblast growth factor receptor (FGFR), vascular endothelial growth factor receptor (VEGFR), plateletderived growth factor receptor (PDGFR), FMS-related tyrosine kinase 3 (FLT3), and SRC, with potential antineoplastic activity. Upon administration, XL999 binds to and inhibits the activity of these TKs, thereby preventing both the activation of downstream signaling pathways and the proliferation of tumor cells overexpressing these TKs. FGFR, VEGFR, PDGFR, FLT -3, and SRC are upregulated in a variety of cancer cell types and play key roles in tumor cell proliferation, angiogenesis, and metastasis. 